\title{
Influence of Gas Flow Speed on Laser Plume Attenuation and Powder Bed Particle Pickup in Laser Powder Bed Fusion
}

\author{
HAOPENG SHEN $₫,^{1,2,4}$ PAUL ROMETSCH, ${ }^{1,2,3}$ XINHUA WU, ${ }^{1,2}$ and \\ AIJUN HUANG ${ }^{1,2,5}$ \\ 1.-Monash Centre for Additive Manufacturing, Notting Hill, VIC 3168, Australia. 2.-Depart- \\ ment of Materials Science and Engineering, Monash University, Clayton, VIC 3800, Australia. \\ 3.-Arvida Research and Development Centre, Rio Tinto, Jonquière, QC G7S 4K8, Canada. \\ 4.-e-mail: haopeng.shen@monash.edu. 5.-e-mail: aijun.huang@monash.edu
}

Using gas flow to reduce laser plume attenuation is critical in the process control of laser powder bed fusion (LPBF) of metal powders. First, this work investigated Hastelloy X (HX) samples built at different gas flow speeds. Higher porosity with lack of fusion defects was found in the samples built at lower gas flow speeds, which indicates a significant influence of laser plume attenuation. Then, particle pickup experiments were conducted to investigate the limit of further increasing the gas flow speed without disturbing the powder bed. Eight different powders of four alloys (Al, Ti, steel, and $\mathrm{Ni}$ ) with mean sizes ranging from $25 \mu \mathrm{m}$ to $118 \mu \mathrm{m}$ were studied. A model was introduced to predict the pickup speeds of different powders. Lastly, a method based on porosity and particle pickup speed was proposed for the reference of setting the lower and upper limits of gas flow speed in LPBF.

\section{INTRODUCTION}

Laser Powder Bed Fusion (LPBF), also known as selective laser melting (SLM), is an advanced additive manufacturing (AM) technology to produce complicated components with high quality. In LPBF, the feedstock powder is spread onto the build platform to form a uniform thin layer of loose particles. Then a laser beam scans the powder bed to melt the loose particles and create reliable bonding with previous layers. Full melting and defect-free solidification require well-controlled energy input for the right amount of material to be melted. However, due to the highly localized melting by a high intensity laser beam, a plume of fine particles formed from evaporated material is a common by-product of the melting process which can attenuate the laser beam. The use of a gas jet to blow away the plume has been widely applied in laser melting processes to ensure the quality of the laser beam and the stability of the melting process. $^{1-4}$ Bidare et al. ${ }^{5}$ visualized the metal vapor plume in LPBF with a high-speed camera and Schlieren imaging. They showed that using a cross flow can effectively remove the plume, but the effectiveness decreases with higher laser power.
Ladewig et al. ${ }^{6}$ found that using a low gas flow rate in a commercial LPBF system (EOS M280) can result in poor surface quality and irregular defects inside the part. However, the gas flow setting they used ( $2 \mathrm{~V}$ and $4 \mathrm{~V}$ ) cannot be readily transferred to the EOS M290 system used in this work as the EOS M290 system used a pressure parameter (in mbar) instead of the voltage parameter in EOS M280. The gas flow speed thus needs to be measured in each machine. Anwar and $\mathrm{Pham}^{7}$ achieved better mechanical properties of AlSi10Mg parts by increasing the gas flow from $30 \%$ to $60 \%$ of the pump setting with an estimated speed increase from $1.43 \mathrm{~m} / \mathrm{s}$ to $2.87 \mathrm{~m} / \mathrm{s}$. Besides increasing the flow speed, it is also important to ensure the uniformity of the gas flow field to avoid low-speed areas. ${ }^{8,9}$ Schniedenharn et al. ${ }^{10}$ conducted detailed flow speed measurements with a hot wire anemometer in a commercial LPBF system. They found that the flow field above the build plate reached a maximum speed of around $4 \mathrm{~m} / \mathrm{s}$ at the inlet side and decreased to about $1 \mathrm{~m} / \mathrm{s}$ at the outlet side. By improving the design of the gas inlet in a commercial LPBF system, Ferrar et al. ${ }^{8}$ achieved a better uniformity of the gas flow field, obtained lower porosity and higher compressive strengths in the $\mathrm{Ti}$ 
parts than the parts built with the original inlet. Wen et al. ${ }^{9}$ also optimized the gas inlet to enable LPBF processing of volatile $\mathrm{Zn}$ powder.

Although some researchers have shown that better LPBF parts can be produced with increased gas flow speed, the speed must be kept below a threshold to avoid disturbing the powder bed. The particle pickup speed, a threshold above which the gas flow picks up loose particles, can be used as a good reference to set the upper limit. Extensive work on particle pickup has been done in fields of pneumatic powder conveying and fluidized powder beds $^{11-18}$. An empirical model developed by Kalman et al. ${ }^{12}$ achieved good agreement with experimental data. This model uses two non-dimensional parameters to correlate pickup speed with powder properties: ${ }^{12}$

$$
\operatorname{Re}_{\mathrm{p}}=\frac{d_{\mathrm{p}} U_{\mathrm{pu}} \rho}{\mu} ; \operatorname{Ar}=\frac{g \rho\left(\rho_{\mathrm{p}}-\rho\right) d_{\mathrm{p}}^{3}}{\mu^{2}}
$$

where $\operatorname{Re}_{\mathrm{p}}$ is the particle Reynolds number, Ar is the Archimedes number, $d_{\mathrm{p}}$ is the particle diameter, $\rho_{\mathrm{p}}$ is the particle density, $U_{\mathrm{pu}}$ is the particle pickup speed of the gas flow, $\rho$ is the gas density, $\mu$ is the gas dynamic viscosity, and $g$ is the gravitational acceleration. For a specific powder, particle pickup occurs if the gas flow goes above the particle pickup speed $U_{\mathrm{pu}}$. The particle pickup speed $U_{\mathrm{pu}}$ is dependent on the powder properties and the gas properties. A powder with a higher $U_{\mathrm{pu}}$ is considered more stable when exposed to a gas flow field. Moreover, to avoid particle pickup of a specific powder, the gas flow speed is considered safe if lower than the threshold $U_{\mathrm{pu}}$. A characteristic diameter is required to account for a gas flow profile different from the baseline gas flow setup (a $50-\mathrm{mm}$ pipe) used to develop the model. ${ }^{12}$ A modified Reynolds number is used to account for different characteristic diameters. The Archimedes number is also modified to account for the particle sphericity: ${ }^{12}$

$$
\begin{aligned}
\operatorname{Re}_{\mathrm{p}}^{*} & =K_{D} \operatorname{Re}_{\mathrm{p}}=\frac{1}{1.4-0.8 e^{-\frac{D / D_{50}}{1.5}}} \operatorname{Re}_{\mathrm{p}} ; \mathrm{Ar}^{*}=K_{\phi} \mathrm{Ar} \\
& =0.03 e^{3.5 \phi} \mathrm{Ar}
\end{aligned}
$$

where $\mathrm{Re}_{\mathrm{p}}^{*}$ is the modified Reynolds number, $K_{D}$ is the flow profile modification factor, $D$ is the characteristic diameter of the gas flow profile above the powder bed, $D_{50}$ is the baseline pipe diameter $(50 \mathrm{~mm}), \mathrm{Ar}^{*}$ is the modified Archimedes number, $K_{\phi}$ is the particle shape modification factor, and $\phi$ is the particle sphericity. Furthermore, $\operatorname{Re}_{\mathrm{p}}^{*}$ is correlated to $\mathrm{Ar}^{*}$ in three different zones: ${ }^{12}$

$$
\begin{aligned}
\text { Zone I : } \quad \operatorname{Re}_{\mathrm{p}}^{*}=5 \mathrm{Ar}^{3 / 7} ; \text { for } \mathrm{Ar}^{*} \geq 16.5 \\
\text { Zone II: } \quad \operatorname{Re}_{\mathrm{p}}^{*}=16.7 \text { f for } 0.45<\mathrm{Ar}^{*}<16.5 \\
\text { Zone III: } \quad \operatorname{Re}_{\mathrm{p}}^{*}=21.8 \mathrm{Ar} *^{1 / 3} ; \text { for } \mathrm{Ar}^{*} \leq 0.45
\end{aligned}
$$

Zone I applies to large particles where gravity is the dominant force. Zone II applies to finer particles where cohesive forces start to become significant. Zone III applies to very fine particles with dominant inter-particle forces. For metal powders, cohesive forces include Van der Waals forces, magnetic forces, electrostatic forces, moisture and the like. ${ }^{19-21}$

The pickup speeds $U_{\mathrm{pu}}^{*}$ can be calculated from $\operatorname{Re}^{*}$. At the transition point between two zones, the transition size and the pickup speed can be calculated:

$$
\begin{aligned}
& d_{\mathrm{I}-\mathrm{II}}^{*}=\left(\frac{16.5 \mu^{2}}{g \rho\left(\rho_{\mathrm{p}}-\rho\right) K_{\phi}}\right)^{1 / 3} ; U_{\mathrm{I}-\mathrm{II}}^{*}=\frac{16.7 \mu}{K_{D} \rho d_{\mathrm{I}-\mathrm{II}}^{*}} \\
& d_{\mathrm{II}-\mathrm{III}}^{*}=\left(\frac{0.45 \mu^{2}}{g \rho\left(\rho_{\mathrm{p}}-\rho\right) K_{\phi}}\right)^{1 / 3} ; U_{\mathrm{II}-\mathrm{III}}^{*}=\frac{16.7 \mu}{K_{D} \rho d_{\mathrm{II}-\mathrm{III}}^{*}}
\end{aligned}
$$

where $d_{\mathrm{I}-\mathrm{II}}^{*}$ is the transition point $\left(\mathrm{Ar}^{*}=16.5\right)$ between Zone I and Zone II, $U_{\text {I-II }}^{*}$ is the pickup speed at the transition point, $d_{\mathrm{II}-\mathrm{III}}^{*}$ is the transition point $\left(\mathrm{Ar}^{*}=0.45\right)$ between Zone II and Zone III, and $U_{\text {II-III }}^{*}$ is the pickup speed at the transition point.

However, this model was developed to predict the lower flow speed limit for powder conveying where particle movement is desired. In LPBF, the aim is to find an upper limit to prevent particle movement on the powder bed. As most of the powders used in the original data to develop the empirical model were non-metal powders, ${ }^{12}$ it is essential to confirm if metal powders behave similarly to non-metal powders. Eight different powders of four typical AM alloys (Al, $\mathrm{Ti}, \mathrm{Fe}$ and $\mathrm{Ni}$ alloys) and different sizes were used in this work to check if the Kalman model is suitable for metal powders used in LPBF.

In summary, previous researchers found that increasing the flow speed and improving the uniformity of the flow field (essentially reducing the low-speed areas) can help to improve the laser melting integrity. However, the suitable speed range that can prevent both severe laser-plume attenuation and disturbance of the powder bed has not been investigated. The current work thus focused on building LPBF samples to study the lower limit of the flow speed and on conducting particle pickup experiments to determine the upper limit of the flow speed.

\section{METHODOLOGY}

\section{LPBF Systems}

To investigate the method to determine the lower limit of the gas flow and the influence of laser plume attenuation, LPBF samples were built in a commercial system (EOS M290) at different gas flow speeds. Argon was used to maintain an inert environment with $<0.1 \%$ oxygen. The gas flow over the scanning 
Table I. Powder properties

\begin{tabular}{|c|c|c|c|c|c|c|c|c|}
\hline Powder & Label $^{\mathbf{a}}$ & $d(10)(\mu \mathrm{m})$ & $d(50)(\mu \mathrm{m})$ & $d(90)(\mu \mathrm{m})$ & $\rho_{p, \text { true }}\left(\mathrm{kg} / \mathrm{m}^{3}\right)$ & $\phi(-)$ & $\dot{V}\left(\mathrm{~mm}^{3} / \mathbf{s}\right)$ & $U_{\text {pu }}(\mathbf{m} / \mathbf{s})$ \\
\hline \multirow[t]{4}{*}{ Hastelloy X } & $\mathrm{Ni}-\mathrm{F} 1{ }^{*}$ & 14.3 & 29.6 & 55.9 & 8353 & 0.94 & $299.3^{\text {tap }}$ & 5.4 \\
\hline & Ni-F2 & 12.3 & 25.4 & 47.4 & - & - & 0 & - \\
\hline & Ni-F3 & 15.5 & 32.8 & 58.8 & - & - & $359.2^{\text {tap }}$ & - \\
\hline & Ni-C1 & 52.7 & 74.4 & 105.6 & 8290 & 0.91 & 458.4 & 7.4 \\
\hline \multirow[t]{2}{*}{ Steel 316L } & Fe-F1 & 18.3 & 36.2 & 65.5 & 7869 & 0.93 & 406.7 & 5.1 \\
\hline & Fe-C1 & 51.2 & 81.6 & 129.9 & 7893 & 0.95 & 405.4 & 7.3 \\
\hline \multirow[t]{3}{*}{ Ti6Al4V } & Ti-F1 & 22.3 & 38.1 & 62.4 & 4406 & 0.95 & 0 & 6.9 \\
\hline & Ti-F2 & 24.9 & 41.0 & 70.1 & - & 0.93 & 295.1 & - \\
\hline & $\mathrm{Ti}-\mathrm{C} 1$ & 54.8 & 102.1 & 183.6 & 4380 & 0.95 & 479.5 & 5.6 \\
\hline \multirow[t]{2}{*}{ AlSi10Mg } & Al-F1 & 18.2 & 34.1 & 58.6 & 2651 & 0.90 & 0 & 5.1 \\
\hline & Al-C1 & 82.4 & 118.1 & 169.1 & 2598 & 0.90 & 346.4 & 4.1 \\
\hline \multirow[t]{2}{*}{ AlSi7Mg } & $\mathrm{Al}-\mathrm{F} 2$ & 22.3 & 37.5 & 61.7 & - & - & 0 & - \\
\hline & Al-F3 & 17.6 & 35.8 & 63.2 & - & - & 0 & - \\
\hline Glass beads & Glass1 & 49.5 & 68.4 & 94.3 & 2459 & 0.98 & 488.0 & 3.9 \\
\hline
\end{tabular}

\begin{tabular}{|c|c|c|c|c|c|c|c|}
\hline Powder & Label $^{\mathbf{b}}$ & $d(10)(\mu \mathrm{m})$ & $d(50)(\mu \mathrm{m})$ & $d(90)(\mu \mathrm{m})$ & $\rho_{\mathrm{p}, \mathrm{nominal}}\left(\mathrm{kg} / \mathrm{m}^{\mathbf{3}}\right)$ & $\dot{V}\left(\mathrm{~mm}^{3} / \mathbf{s}\right)$ & References \\
\hline \multirow[t]{3}{*}{ AlSi7Mg } & $\mathrm{Al}-\mathrm{X} 1$ & 48 & 63 & 83 & \multirow[t]{6}{*}{2660} & 569.3 & \multirow[t]{3}{*}{23} \\
\hline & $\mathrm{Al}-\mathrm{X} 2$ & 54 & 70 & 91 & & 573.0 & \\
\hline & $\mathrm{Al}-\mathrm{X} 3$ & 14 & 31 & 58 & & 0 & \\
\hline \multirow{3}{*}{ AlSi12Mg } & $\mathrm{Al}-\mathrm{X} 4$ & 24 & 48 & 71 & & 287.0 & \multirow[t]{3}{*}{24} \\
\hline & $\mathrm{Al}-\mathrm{X} 5$ & 17 & 42 & 85 & & 0 & \\
\hline & $\mathrm{Al}-\mathrm{X} 6$ & 22 & 60 & 94 & & 260.3 & \\
\hline \multirow{12}{*}{ Ti6Al4V } & Ti-X1 & 52.5 & 78.9 & 113 & \multirow[t]{12}{*}{4400} & 425.0 & \multirow[t]{6}{*}{25} \\
\hline & Ti-X2 & 38.1 & 64.6 & 102 & & 434.1 & \\
\hline & Ti-X3 & 54.1 & 100.6 & 146 & & 463.6 & \\
\hline & $\mathrm{Ti}-\mathrm{X} 4$ & 51 & 67.8 & 95 & & 422.7 & \\
\hline & Ti-X5 & 49 & 63.6 & 93 & & 427.3 & \\
\hline & $\mathrm{Ti}-\mathrm{X} 6$ & 57.8 & 70.3 & 95 & & 429.5 & \\
\hline & Ti-X7 & 12 & 56 & 86 & & 459.1 & \multirow[t]{3}{*}{26} \\
\hline & Ti-X8 & 43 & 56 & 86 & & 552.3 & \\
\hline & Ti-X9 & 41 & 68 & 111 & & 440.9 & \\
\hline & Ti-X10 & 30.6 & 44.7 & 54.5 & & 431.2 & \multirow[t]{3}{*}{27} \\
\hline & Ti-X11 & 31 & 42.2 & 55.1 & & 500.8 & \\
\hline & Ti-X12 & 25.4 & 40.1 & 54.7 & & 0 & \\
\hline \multirow[t]{8}{*}{ Inconel 718} & Ni-X1 & 55 & 75.7 & 104 & \multirow[t]{8}{*}{8200} & 480.5 & \multirow[t]{8}{*}{28} \\
\hline & $\mathrm{Ni}-\mathrm{X} 2$ & 53.7 & 72.9 & 100 & & 369.5 & \\
\hline & $\mathrm{Ni}-\mathrm{X} 3$ & 48.7 & 66.3 & 90 & & 461.0 & \\
\hline & $\mathrm{Ni}-\mathrm{X} 4$ & 48.1 & 65.4 & 90 & & 404.9 & \\
\hline & $\mathrm{Ni}-\mathrm{X} 5$ & 53.8 & 72.7 & 99 & & 391.5 & \\
\hline & $\mathrm{Ni}-\mathrm{X} 6$ & 21.4 & 31.2 & 49.5 & & 214.6 & \\
\hline & $\mathrm{Ni}-\mathrm{X} 7$ & 21.9 & 32.4 & 50.7 & & 207.3 & \\
\hline & $\mathrm{Ni}-\mathrm{X} 8$ & 18.5 & 33.9 & 47 & & 302.4 & \\
\hline \multirow[t]{2}{*}{ Inconel 625} & $\mathrm{Ni}-\mathrm{X} 9$ & 16 & 27 & 48 & \multirow[t]{2}{*}{8440} & 340.5 & \multirow[t]{2}{*}{31} \\
\hline & Ni-X10 & 81 & 110 & 150 & & 0 & \\
\hline
\end{tabular}

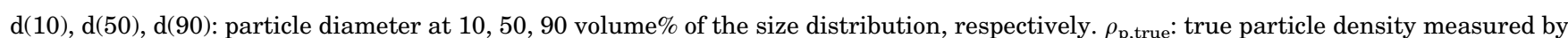
helium pycnometer. $\rho_{\mathrm{p}, \text { nominal }}$ : nominal particle density, used when true particle density is not available. $\phi$ : particle sphericity from $2 \mathrm{D}$ image analysis (Cox circularity). Mean value of the number distribution. $\dot{\boldsymbol{V}}$ : volume flow rate from Hall flow tests. 0 means non-flowing. Conversion to mass flow rate $=\dot{\boldsymbol{V}} \rho_{\mathrm{p}}(\mathrm{g} / \mathrm{s})$ and Hall flow time $=50 / \boldsymbol{M}(\mathrm{s} / 50 \mathrm{~g}) .{ }^{\text {tap }}$ : tapping is required to initiate free flow in some tests. $U_{\mathrm{pu}}$ :

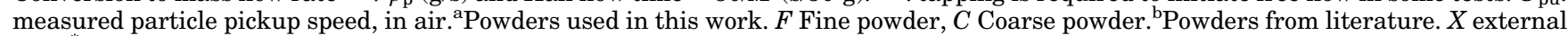
data."Used for the LPBF printing in EOS M290.

area was adjusted by setting different "turbine pressure" parameters (defined in the EOS control software) within the standard operating range $(0.1$ to $1 \mathrm{mbar})$. A Ni-alloy Hastelloy X (HX) powder was used to build samples in the EOS M290 system. The powder was sieved with a $63-\mu \mathrm{m}$ mesh to remove coarse particles. The properties of the powder, labeled as Ni-F1, are shown in Table I. The process parameters have been optimized for this powder to achieve an average porosity lower than $0.5 \%$. However, the porosity of samples built at different positions on the build platform fluctuated from 


\section{(a)EOS M290 top view}

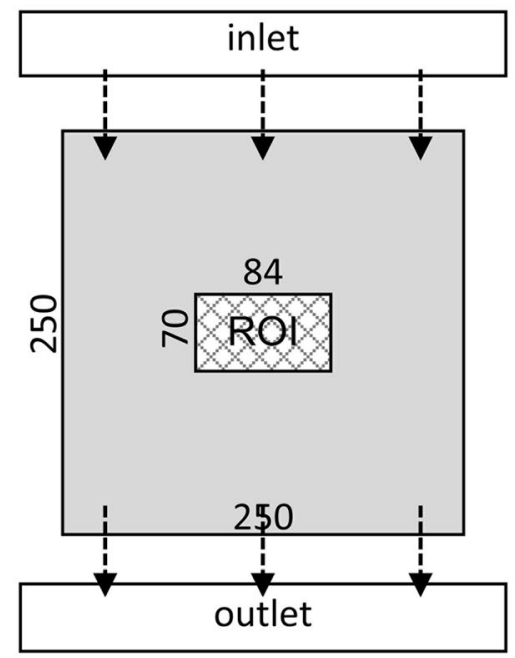

(b) AmPro SP500 top view

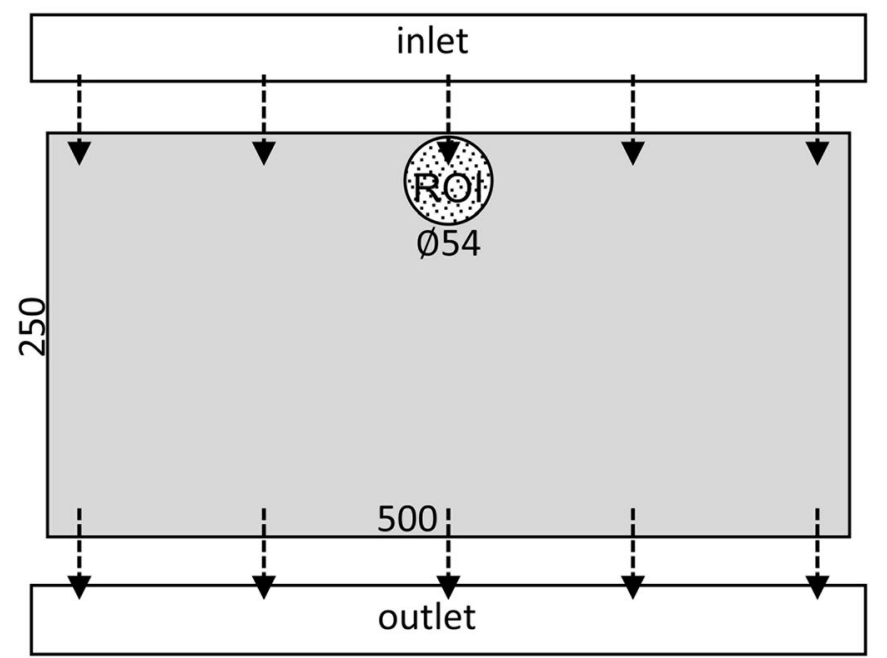

Fig. 1. Schematic diagram of (a) study of laser plume attenuation in EOS M290 and (b) particle pickup tests in AmPro SP500. Region of interest (ROI) is (a) at the center (b) at the inlet-side edge of the build platform. Dimensions are in $\mathrm{mm}$. Arrows indicate the nominal main flow direction (from inlet to outlet).

$0.1 \%$ to $0.5 \%$. It is believed that the fluctuation of the porosity is related to the variation of the gas flow field over the powder bed, which inspired this work. The laser power, scan speed, and layer thickness were $311 \mathrm{~W}, 960 \mathrm{~mm} / \mathrm{s}$, and $0.04 \mathrm{~mm}$, respectively. Bi-directional scanning and $90^{\circ}$ interlayer rotation were used to build the samples (10 mm width and $6 \mathrm{~mm}$ height). All HX samples were built with the same process parameters and at the center of the EOS M290 build plate to avoid the influence of non-uniformities from the gas flow field as in Fig. 1a.

To investigate the upper limit of the gas flow, particle pickup experiments were conducted in another LPBF system (AmPro SP500, developed by AmPro Innovations) as the gas flow speed inside the EOS M290 system is limited and initial trials at the highest gas flow setting $(1$ mbar) showed no obvious powder loss. The AmPro system uses an optimized gas flow design and a more powerful pump, which enables a flow up to $10 \mathrm{~m} / \mathrm{s}$. This machine also has better linearity between measured flow speed and pump speed, as shown in the supplementary Fig. S-1 (refer to online supplementary material). The particle pickup experiment was based on a weight-loss method. ${ }^{12,13}$ In each test, a small powder bed was prepared in a container (54 $\mathrm{mm}$ diameter and $6 \mathrm{~mm}$ depth) and then placed into the chamber and exposed to the flow for $5 \mathrm{~min}$ at a fixed position on the build plate, as shown in Fig. 1b. The powder bed was tapped during powder adding and the last few layers were spread evenly with a steel blade. An analytical balance with $0.1 \mathrm{mg}$ precision (Mettler Toledo ME204) was used to weigh the powder bed before and after pickup. Air was used during the particle pickup test as no laser scanning was involved. The conversion of particle pickup speed in air to that in argon is discussed in the modeling part.

\section{Powders}

Eight metal powders were used to conduct the particle pickup test in AmPro SP500, covering four types of common alloys used in AM, namely $\mathrm{Al}$, Ti, steel and Ni alloys. One Ni-alloy powder (Ni-F1) was used to build samples in EOS M290 to investigate the influence of laser plume attenuation and to determine the lower limit of the gas flow speed. A reference powder of spherical glass beads was included as it is widely use in particle pickup studies. ${ }^{12-14}$ The characteristic diameter of the gas flow profile above the powder bed was first calculated based on the pickup speed of the reference powder and then used to predict the pickup speeds of other powders. Morphologies of the powders are shown in Fig. 2 and properties are listed in Table I.

\section{Characterization}

Gas flow speed inside the LPBF chambers was measured with a vane anemometer $(30 \mathrm{~mm}$ vane, $0.4-30 \mathrm{~m} / \mathrm{s}$ range, $0.1 \mathrm{~m} / \mathrm{s}$ resolution). The anemometer has been calibrated in both air and argon by the manufacturer. It was placed close to the build plate facing the inlet-outlet main flow direction. All measurements of gas flow speeds were conducted at room temperature without build plate heating as the anemometer was calibrated at room temperature only.

The porosity of the as-built samples was analyzed with a Nikon Eclipse Ni optical microscope (OM). After LPBF buildings, the samples were cut off from the plate and sectioned via electrical discharge machining (EDM), then hot-mounted and polished 

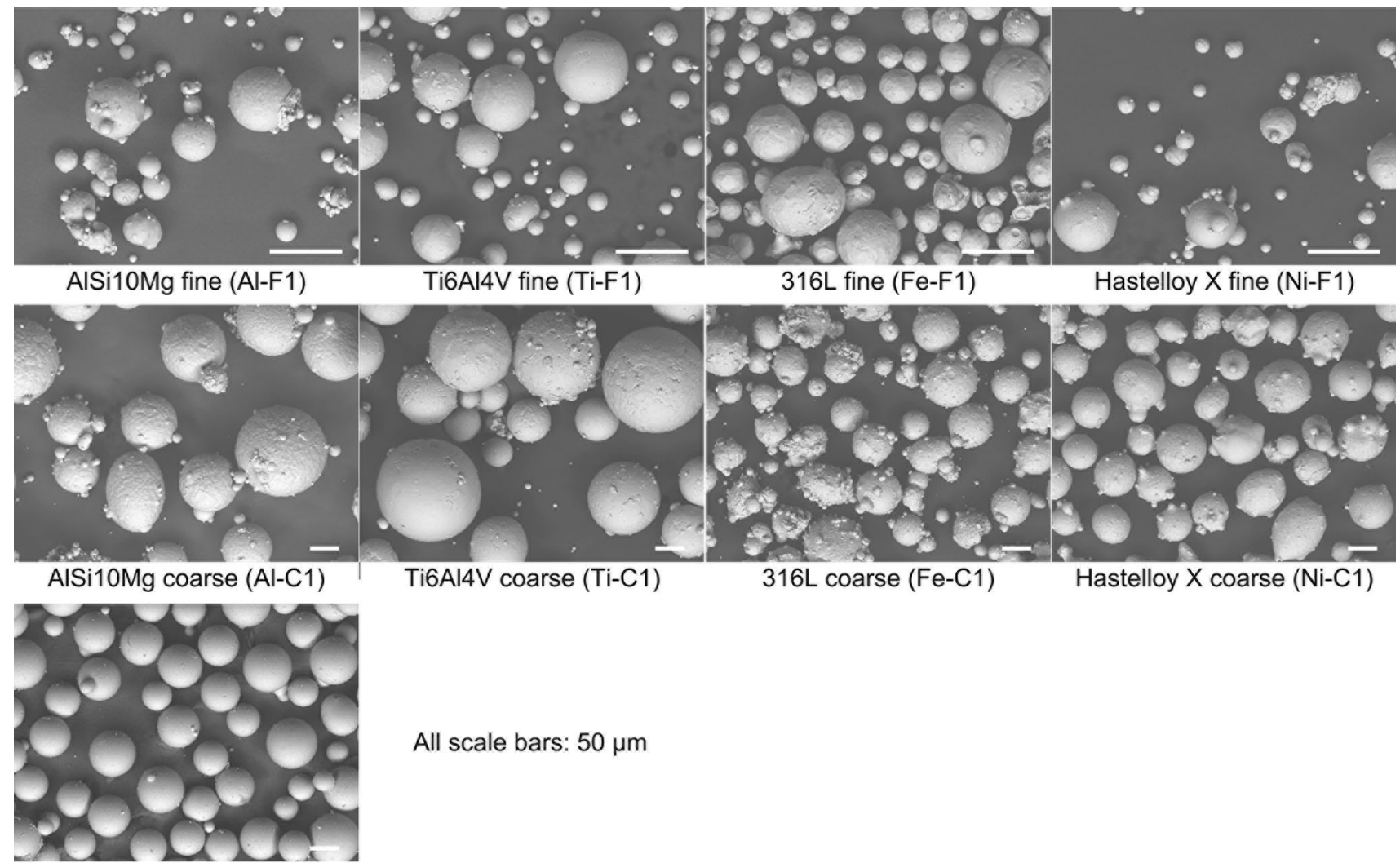

Glass beads (Glass1)

All scale bars: $50 \mu \mathrm{m}$

Fig. 2. SEM images of powders used in the particle pickup experiment.

using a Struers Tegramin-30 automated polisher. For each gas flow speed, at least 4 polished samples and at least 25 images $(1.7 \mathrm{~mm}$ by $1.3 \mathrm{~mm})$ from each sample were analyzed. Some samples were electro-etched in a solution of $10 \mathrm{~g}$ oxalic acid and $100 \mathrm{ml}$ distilled water. A JEOL JSM-7001F scanning electron microscope (SEM) was used for highmagnification characterization. The glass beads were coated with carbon before SEM observation.

Powder size distribution, true particle density, particle sphericity and powder flowability were characterized, as listed in Table I. Powder size distributions were measured via laser diffraction (Malvern Mastersizer-2000 with a dry unit). The particle size at $50 \%$ of the volume distribution was used to represent the powder size unless otherwise stated. The powder morphology was analyzed with an automated microscopic particle analyzer (Malvern Morphologi-G3). The 2D Cox circularity was used to represent particle sphericity, as recommended by Bagheri et al. ${ }^{22}$ Metal powders used in this work were gas atomized for AM applications and are commercially available. The true particle density was analyzed with a helium pycnometer (AccuPyc 1330). Flowability was measured with a standard Hall flowmeter (ASTM B123) for at least five measurements of each powder. Instead of reporting the flow time required to drain $50 \mathrm{~g}$ of powder $(\mathrm{s} / 50 \mathrm{~g})$, a volume flow rate $\left(\mathrm{mm}^{3} / \mathrm{s}\right.$, sample weight divided by flow time and particle density) was used to compare powders of different densities.

\section{RESULTS}

\section{Lower Limit of Flow Speed}

The lower limit of flow speed was found to be around $1.5 \mathrm{~m} / \mathrm{s}$ for HX based on the porosity result, as shown in Fig. 3a. All the HX samples were built with the same process parameters and at the same area (ROI in Fig. 1a) on the EOS M290 build platform. Only the "turbine pressure" was set at different values within the standard operating range (0.1-1 mbar). Below $1 \mathrm{~m} / \mathrm{s}$, severe laser plume attenuation resulted in large defects upon laser melting (Fig. 3b). These defects have typical lack-of-fusion features of a large size and irregular shape. ${ }^{32,33}$ In addition, the long axis is oriented perpendicular to the build direction. Above $1.5 \mathrm{~m} / \mathrm{s}$, the mean value and the scattering (represented by error bars of one standard deviation) further decrease as the gas flow speed increases, and the best solidification quality was achieved at $2.1 \mathrm{~m} / \mathrm{s}$ flow speed (at $1 \mathrm{mbar}$, maximum of the pump speed setting). At $2.1 \mathrm{~m} / \mathrm{s}$, the porosity was pushed to the lowest level, with only some small pores and microcracks. HX is known to be susceptible to cracking during LPBF because of the high cooling rate. ${ }^{34,35}$ Moreover, the laser-plume attenuation also contributed to the cracking as some lack-of-fusion 


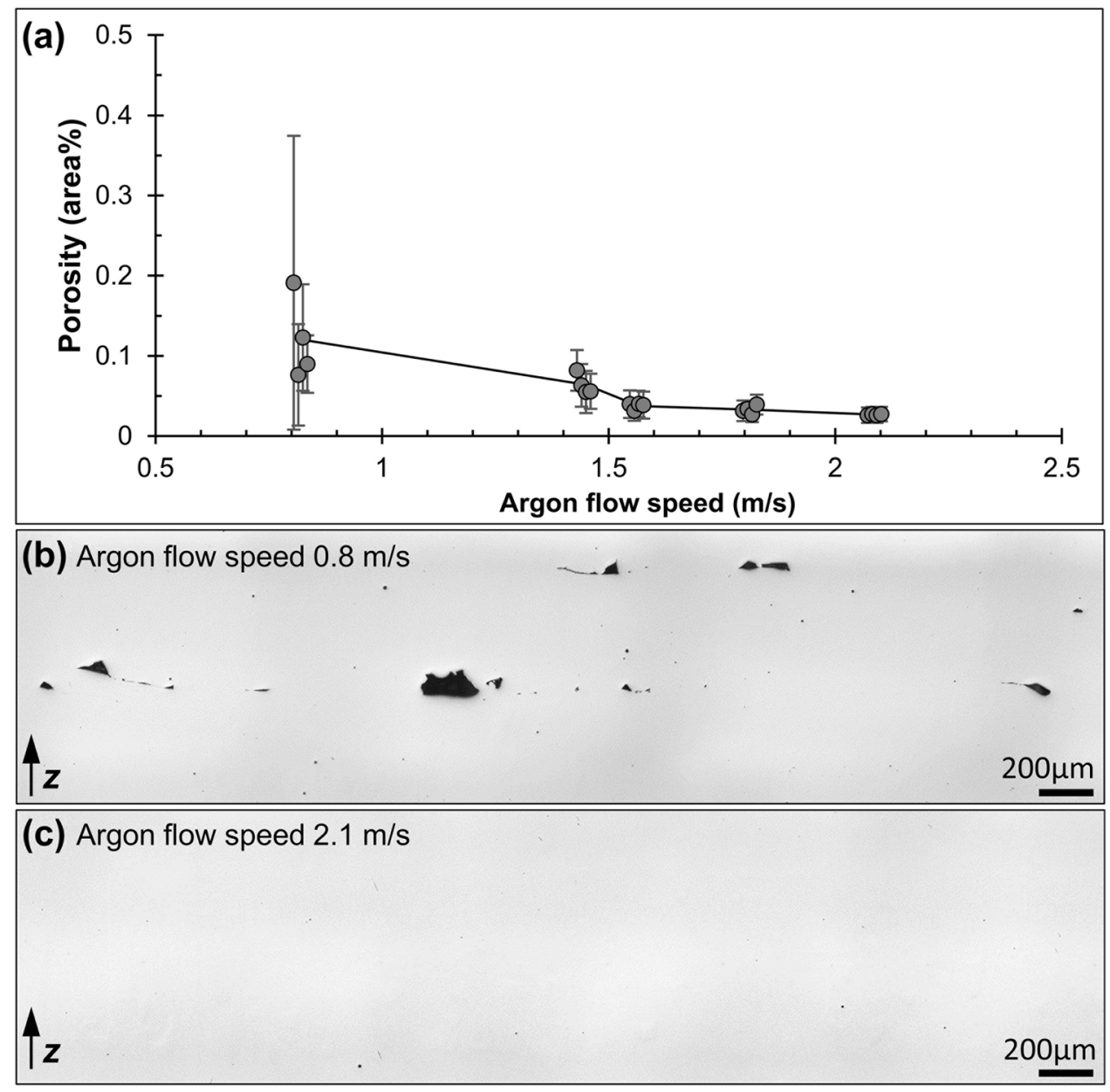

Fig. 3. (a) Porosity in HX samples built at different argon flow speeds in EOS M290. Error bars show one standard deviation from the mean of at least 25 images. The solid line connects the averaged values. Stitched optical micrographs of over 20 layers and 150 scan tracks show (b) lackof-fusion defects in samples built at low flow speed, and (c) no significant defects at high flow speed. Arrows show the build direction.

defects with sharp corners were found to be associated with the cracks, as shown in supplementary Fig. S-2.

The plume particles condensed from the vapor are much smaller than the metal powder, as shown in supplementary Fig. S-3. These nano-particles follow the gas flow well and are therefore sensitive to changes in flow speed. As shown in a visualization of the plume in LPBF, ${ }^{5}$ a cross flow can effectively remove the plume from the laser path and reduce the laser-plume interaction length. Therefore, the melting process will benefit from reduced laser plume attenuation at high gas flow speed. .,36,37 $^{-1}$ However, the gas flow speed must be regulated below a certain limit, otherwise the gas flow can disturb the powder bed and pick up the loose particles.

\section{Upper Limit of Flow Speed}

\section{Particle Pickup Speed}

As the flow speed increases, the powder bed becomes unstable and weight loss occurs due to particle pickup. The weight losses and volume losses of various powders under different airflow speeds are shown in Fig. 4a and b. Powder beds made of fine $\mathrm{Al}$ and $\mathrm{Ti}$ alloys showed higher stability than the corresponding coarse powder. The $\mathrm{Fe}$ and $\mathrm{Ni}$ alloys showed the opposite trend, with the coarse powder being more stable than the fine powder. This implies that the upper limit of the gas flow speed in the LPBF of metal powders cannot be based on the intuitive assumption that a powder bed made of heavier particles (of higher density or larger size) is more stable under the gas flow.

The pickup speed is defined as the critical speed above which the gas flow picks up loose particles from the powder bed. To determine the critical pickup speed, the mean and standard deviation of at least five measurements conducted at low speed $(0-$ $1 \mathrm{~m} / \mathrm{s}$ ) were calculated. Then the threshold was set as the mean plus three standard deviations to account for errors of the methodology. Assuming a normal distribution, this gives a $99.7 \%$ confidence to determine if a weight loss higher than the threshold is actually caused by a pickup event. As shown in 

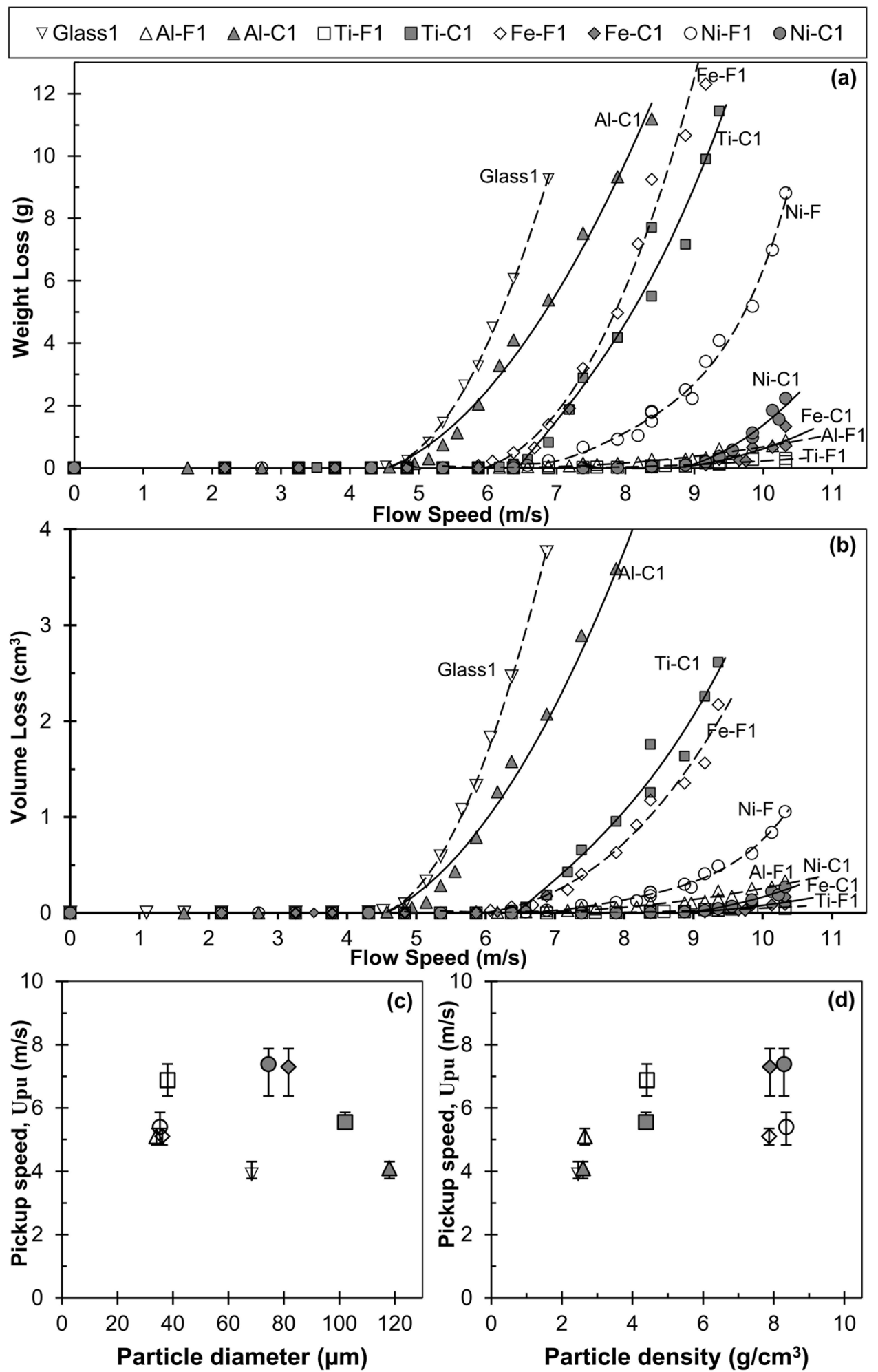

Fig. 4. Plots of (a) weight loss and (b) volume loss (weight loss/particle density) of different powders at different air flow speeds. Pickup speeds determined from weight loss curves plotted against (c) particle size and (d) particle density.

Fig. 4c and d, similar to the weight loss curves, the pickup speeds do not follow a simple monotonic relationship with particle density or particle size. Instead, it was found that the Kalman model can give a better prediction.
Before using the Kalman three-zone model to predict pickup speeds, the reference material (spherical glass beads) was used to calculate the characteristic diameter. Using the as-measured pickup speed, powder properties for glass beads 

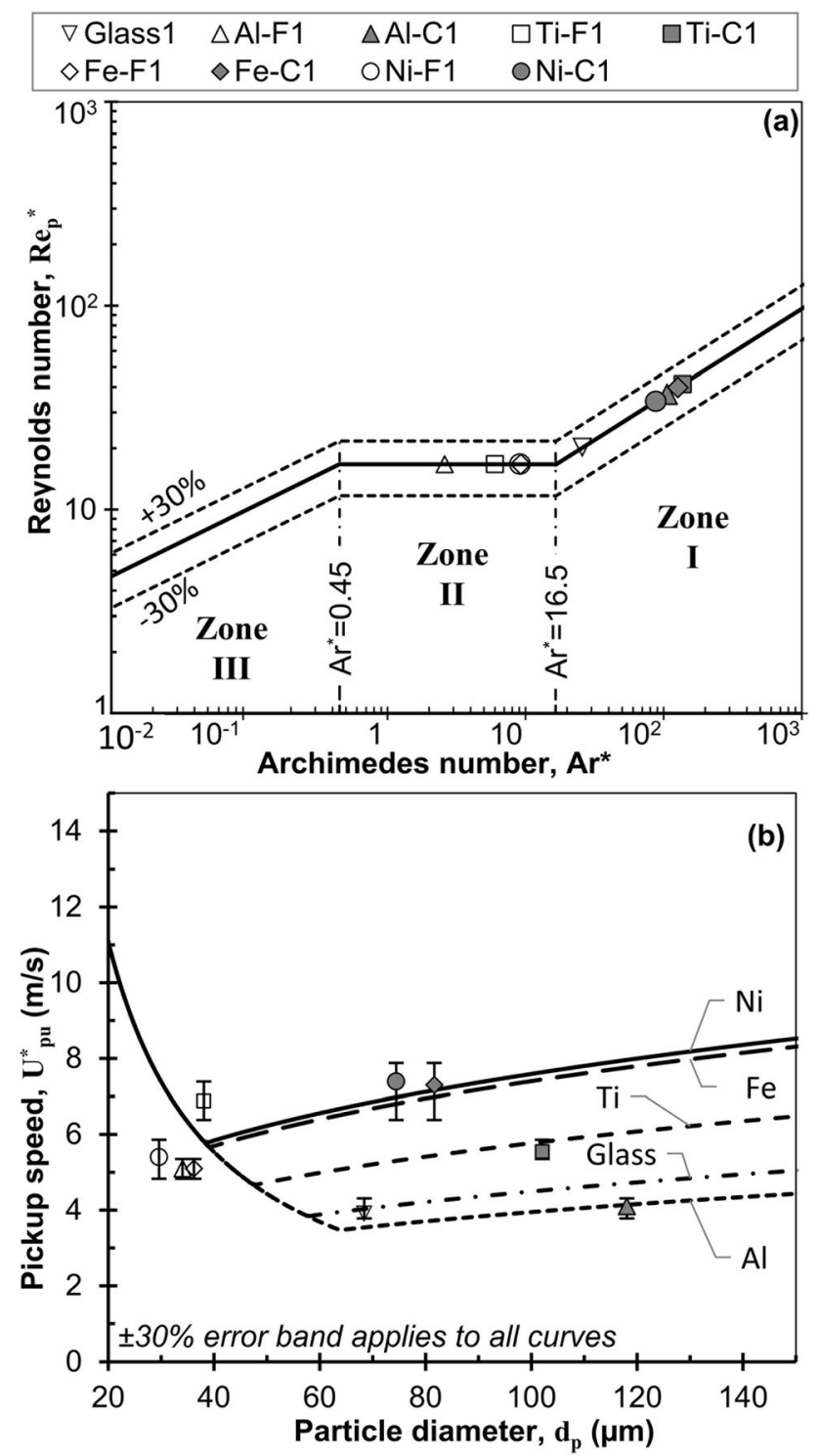

Fig. 5. (a) Agreement of measured data of test powders with the Kalman model using non-dimensional parameters and three zones. (b) Agreement of pickup flow speed between measurements (scatter points) and predictions (curves) in airflow.

(Table I), and air properties, the characteristic diameter D was calculated from Eqs. 1, 2, 3, 4 and 5 and was found to be $31 \mathrm{~mm}$, which is close to the $30 \mathrm{~mm}$ diameter of the vane anemometer used for flow speed measurements. In the gas flow field in $\mathrm{LPBF}$, the characteristic diameter is dependent on the flow velocity profile above the build plate. With known particle properties, gas properties and characteristic diameter, the pickup speed can then be calculated for other powders from Eqs. 1, 2, 3, 4 and 5.

The metal powders used in this work fit well with the Kalman three-zone model (Fig. 5a), which proves that the metal powders follow a similar rule as the powders (mostly non-metal powders) that were used to develop this empirical model. Figure $5 \mathrm{~b}$ shows that the predicted pickup speeds have

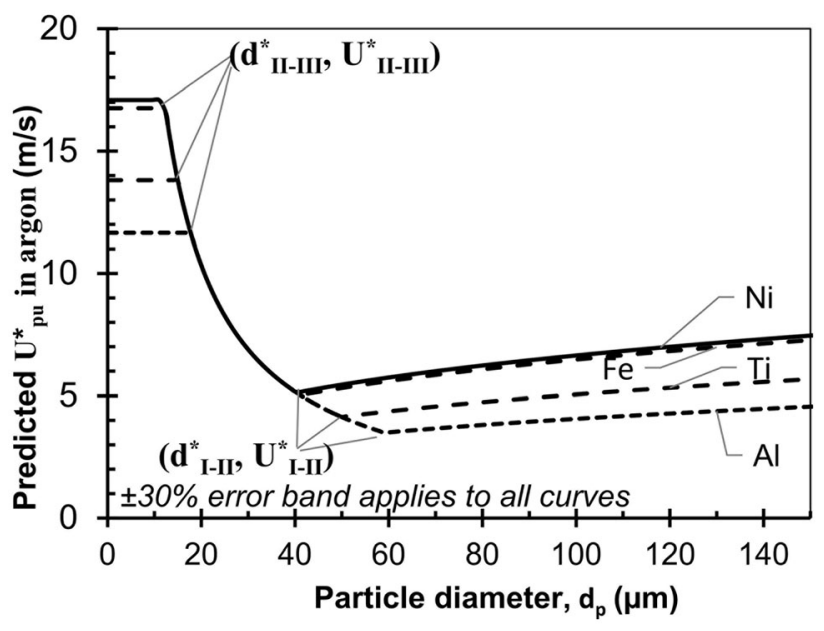

Fig. 6. Predicted pickup speeds of different alloys in argon flow using the Kalman three zone model. $d_{1-||}^{*}$ and $d_{11-1 \mid}^{*}$ are the transition sizes at $\mathrm{Ar}^{\star}=0.45$ and $\mathrm{Ar}^{*}=16.5$ in Fig. $5 \mathrm{a}$, respectively. $U_{|-| l}^{*}$ and $U_{\|-\mid I I}^{*}$ are the pickup speeds at $d_{|-| \mid}^{*}$ and $d_{\|-|| l}^{*}$, respectively.

a reasonable agreement with the measurements, considering the empirical model has an inherent $\pm 30 \%$ error band. ${ }^{12}$ Pickup speed in argon flow can be calculated by substituting the properties of air to argon. As argon has a higher density and viscosity than air, the pickup speed is slightly lower in argon than in air. Figure 6 shows the pickup speeds of four representative material densities (Al, $\mathrm{Ti}, \mathrm{Fe}$ and $\mathrm{Ni}$ alloys) as a function of particle size using argon properties and the $31 \mathrm{~mm}$ characteristic diameter calculated from the pickup speed of the glass beads.

\section{DISCUSSION}

\section{Cohesive Forces}

Based on the good agreement between the results of the particle pickup experiment and the Kalman three-zone model, it is believed that the size dependent cohesive forces play an important role in the particle pickup of fine metal powders, similar to the non-metal powders reported in. ${ }^{11-18}$ As shown in Fig. 6, in Zone III $\left(\mathrm{Ar}^{*}<0.45\right)$, due to the dominant cohesive forces in the very fine powders (smaller than $d_{\mathrm{II}-\mathrm{III}}^{*}$, about $<20 \mu \mathrm{m}$ ), the powder bed has a very high stability with pickup speeds above $10 \mathrm{~m} / \mathrm{s}$. In Zone II $\left(0.45<\mathrm{Ar}^{*}<16.5\right)$, the pickup speed decreases sharply with increasing particle size as the size-dependent cohesive forces decrease. At the transition point $d_{\mathrm{I}-\mathrm{II}}^{*}$, the pickup speed reaches the minimum $U_{\mathrm{I}-\mathrm{II}}^{*}$. Beyond $d_{\mathrm{I}-\mathrm{II}}^{*}$, the powder enters Zone I $\left(\mathrm{Ar}^{*}>16.5\right)$ where gravity becomes dominant; therefore, the pickup speed increases with increasing particle size as heavier (larger) particles will be harder to be picked up. According to the model, the minimum pickup speed occurs at the transition point between Zone I (dominated by gravity) and Zone II (with significant cohesive forces). The particle size and the pickup speed at 

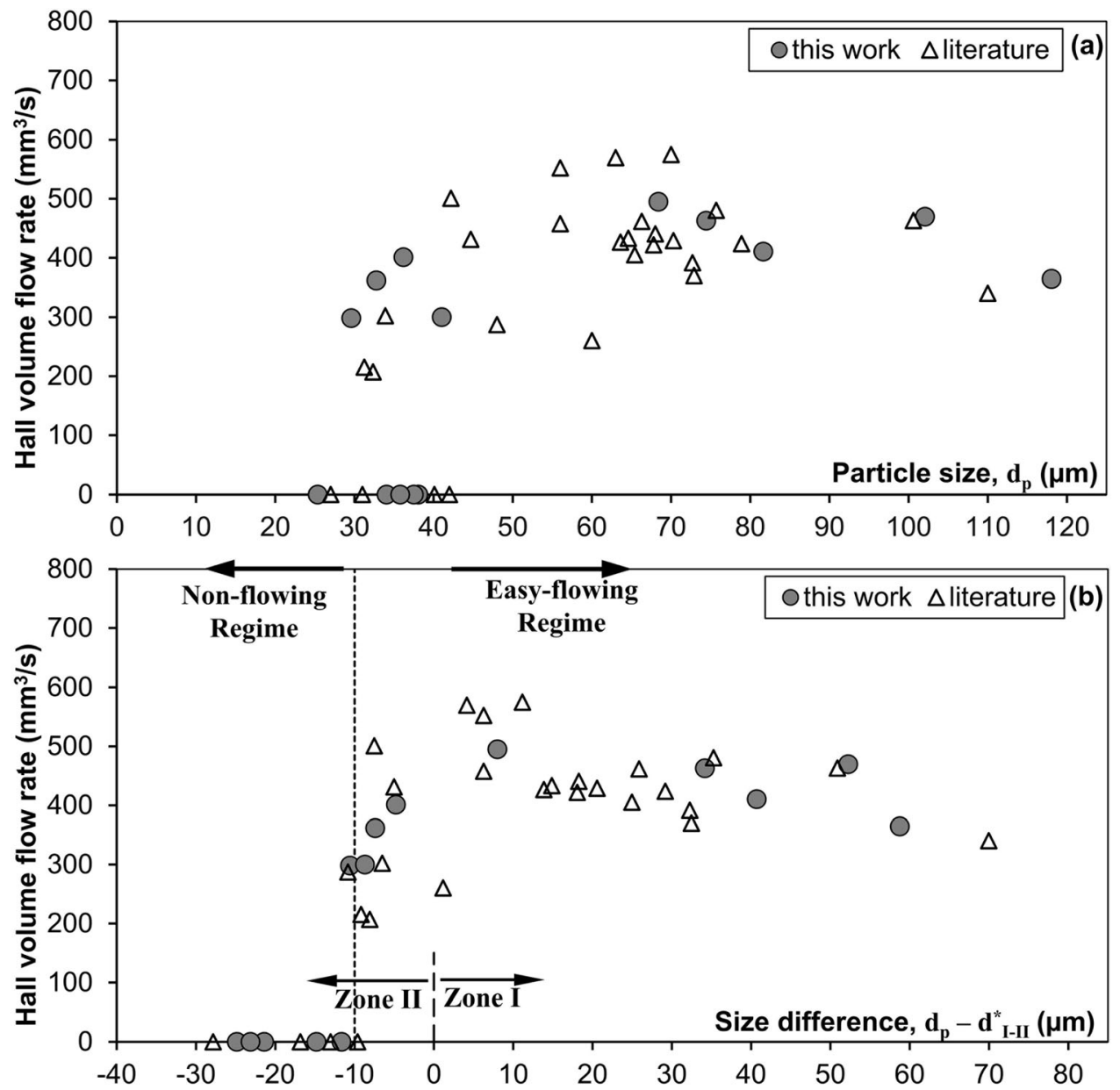

Fig. 7. (a) Flowability plotted against powder size, showing that within about $30-40 \mu \mathrm{m}$ both non-flowing and flowing powders exist; (b) flowability plotted against $d_{p}-d_{|-| l}^{*}$, the difference between the particle size $d_{p}$ and the transition size $d_{|-| l}^{*}$. Literature data are listed in Table I.

the transition point are dependent on the particle density. In argon, the heavy $\mathrm{Ni}$ and $\mathrm{Fe}$-alloy have a minimum pickup speed $U_{\text {I-II }}^{*}$ of about $5 \mathrm{~m} / \mathrm{s}$ at a transition particle size $d_{\mathrm{I}-\mathrm{II}}^{*}$ of about $40 \mu \mathrm{m}$, the lighter Ti-alloy has $4.1 \mathrm{~m} / \mathrm{s} U_{\text {I-II }}^{*}$ at about $50 \mu \mathrm{m}$ $d_{\mathrm{I}-\mathrm{II}}^{*}$, and the lightest Al-alloy has $3.5 \mathrm{~m} / \mathrm{s} U_{\mathrm{I}-\mathrm{II}}^{*}$ at about $60 \mu \mathrm{m} d_{\mathrm{I}-\mathrm{II}}^{*}$.

Cohesive forces increase the powder bed stability (particle pickup speed) but reduce the flowability of fine powders. As shown in Fig. 7a, common AM powders of mean size over $50 \mu \mathrm{m}$ can flow easily with negligible influence of cohesive forces. In Zone I, the particle pickup speed of coarse powders $\left(d_{\mathrm{p}}>d_{\mathrm{I}-\mathrm{II}}^{*}\right)$ decreases as the particle size decreases, as depicted in Fig. 6. As the powder size starts to enter Zone II of the pickup model, cohesive forces start to affect the flowability which fluctuates between free-flowing and non-flowing and becomes sensitive to powder properties that affect the cohesive forces (e.g., powder size distribution, particle shape, and moisture). With a further decrease in powder size (about $<30 \mu \mathrm{m}$ ), the cohesive forces become dominant and the powder enters the nonflowing regime in the Hall flow test. Figure $7 \mathrm{~b}$ shows that the flowability can be better correlated to the difference between the particle size $d_{\mathrm{p}}$ and the transition size $d_{\mathrm{I}-\mathrm{II}}^{*}\left(d_{\mathrm{p}}-d_{\mathrm{I}-\mathrm{II}}^{*}\right)$, which indicates how deep the powder enters the cohesive zone. As the particle size decreases below about $d_{\mathrm{I}-\mathrm{II}}^{*}-10 \mu \mathrm{m}$, the powder enters the non-flowing regime in the Hall flow test. Non-flowing powders are generally incompatible with hopper-based powder feeding. Moreover, poor flowability can make it challenging to achieve homogenous layers during powder recoating. ${ }^{38}$ In Zone III, due to the dominant cohesive forces, the powder has very high pickup speed but no flowability and tends to agglomerate. Pleass and Jothi $^{39}$ showed that it is impossible to spread powder layers with a very fine Ni-alloy powder (5$9 \mu \mathrm{m}$ IN625) in the commercial LPBF system they used, due to severe particle agglomeration. Good powder flowability is critical in powder recoating, hopper-based dosing, and automated powder handling. Therefore, fine powders with less cohesive forces are favored in future industrial LPBF productions, which means that the powder size is likely to move closer to the transition point $d_{\mathrm{I}-\mathrm{II}}^{*}$ (Fig. 7). Furthermore, for the design and operation a LPBF 


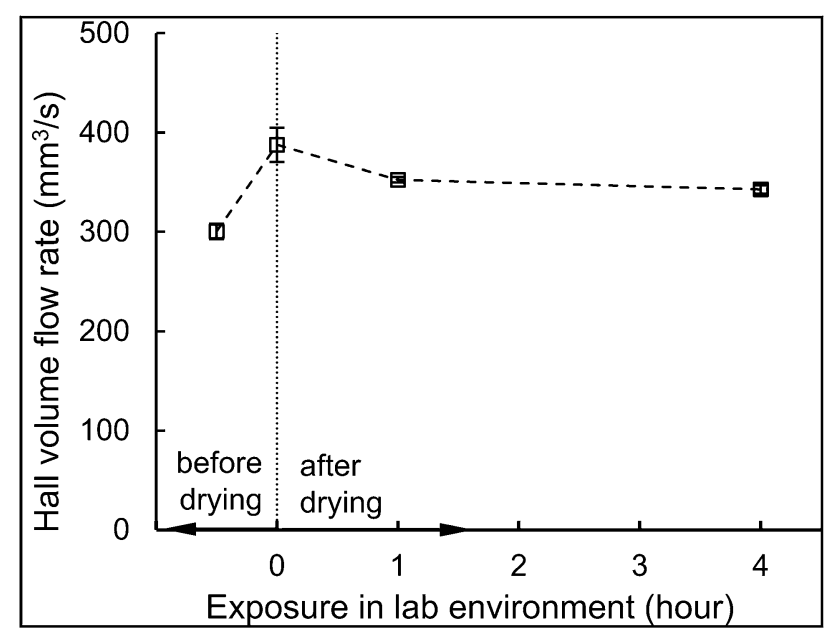

Fig. 8. Flowability increases after drying of as-bottled Ti64 powder and decreases with increasing exposure time to the laboratory environment. Error bars show one standard deviation from the mean of at least three measurements.

gas flow system, the minimum pickup speed $U_{\text {I-II }}^{*}$ (Fig. 6) of a certain material should be used as a reference to set the upper limit of the gas flow over the build platform.

Also, powder drying is likely to become a standard practice in LPPF products to avoid hydrogen pores. ${ }^{40-42}$ Removing the moisture can also reduce the cohesive forces and the particle pickup speed as well. The drying effect of Ti6Al4V (Ti64) powder (TiF2) on flowability is shown in Fig. 8. Before drying, the as-bottled powder had a flowability of about $300 \mathrm{~mm}^{3} / \mathrm{s}$ and a moisture level of $0.01 \%$ to $0.03 \%$ in weight. The flowability of the dried powder increased to $388 \mathrm{~mm}^{3} / \mathrm{s}$ and the moisture level was lower than $0.01 \%$ (detection limit of the moisture analyzer Sartorius MA37). Drying the powder reduces the cohesive forces in the powder so the flowability increases, and therefore reduces the particle pickup speed. As the powders used in this work were in as-bottled storage condition, particle pickup experiments of dried metal powder should be considered in future work.

\section{Effect of Particle Pickup}

The particle pickup experiments conducted in the AmPro SP500 system were exposed to the gas flow for about 5 min to allow the gas flow field to settle down and enough mass loss of the small powder bed to be detected by the balance. However, the particle pickup actually can happen within a much shorter time in during a LPBF printing. Video frame images in Fig. 9a, b, c and d show a particle pickup event captured during a printing in another commercial LPBF system (hereafter called "LPBF-X"). The gas flow setting, powder and process parameters were provided by the system manufacturer. The "LPBFX" system features four-laser scanning and automated powder handling. In multi-laser scanning and high-build-rate production, due to a large amount of material evaporation, a high gas flow speed is crucial for effective plume removal to avoid attenuation of all four laser beams and possible contamination of the laser window. The position of the pickup site is close to the inlet where a higher flow speed is expected compared to other areas on the powder bed, similar to the commercial system characterized in. ${ }^{10}$ The powder loss on the solidified surface was easy to see, thanks to the contrast between the powder layer (bright grey) and the solidified surface (dark). It is possible that pickup also happened at other positions on the powder bed, but without a high-end camera, it is hard to visualize the movement of loose particles when the contrast is low (thin powder loss or no underlying solidified surface). The powder was Ti64 within a 20 $\mu \mathrm{m}$ to $53 \mu \mathrm{m}$ sieve size. Small particles $(<20 \mu \mathrm{m})$ were sieved out to achieve good flowability, which is required by the hopper-based dosing used in this machine.

In addition, it is found that if the powder loss on the laser scanning area lasts over about five to ten layers, the build job may be immediately stopped due to significant shape defects. For occasional powder thickness fluctuations over a few layers, the printing job can finish without visible surface defects but internal defects can be found in the solidification (Fig. 10a). Regarding the position on the build plate, nearly all powder pickup events happened at the inlet side where higher flow speed is expected. It is also worth mentioning that most of the pickup events did not happen right after the powder recoating but with a delay (Fig. 9a, b and c). Besides possible fluctuations of the gas flow field, the in situ heating on the scanned area may explain the delay of the particle pickup as the delay allowed the particles to heat up on the hot underlying solidified surface, and dried particles have weaker inter-particle forces and thus are more easily picked up. Also, it is necessary to conduct a detailed study of the gas flow profile along the vertical direction, which can also significantly affect the particle pickup behavior.

\section{Defects Due to Inappropriate Gas Flow Speed}

At low gas flow speed, the laser plume attenuation can result in a significant loss of laser power. Lack of fusion defects thus can form inside the part due to insufficient effective energy input: $E_{\text {effective }}=(P-\Delta P) / h v l$, where $P$ is the nominal laser power (i.e., setting power), $\Delta P$ is the power loss due to laser-plume attenuation, $h$ is the hatch distance, and $l$ is the nominal layer thickness. Here, the effective energy density is used as a straightforward explanation of the type of defects formed inside the part. The actual interactions among the melt pool, laser plume and the laser beam can be very complicated and usually are dependent on the material properties and process parameters. 

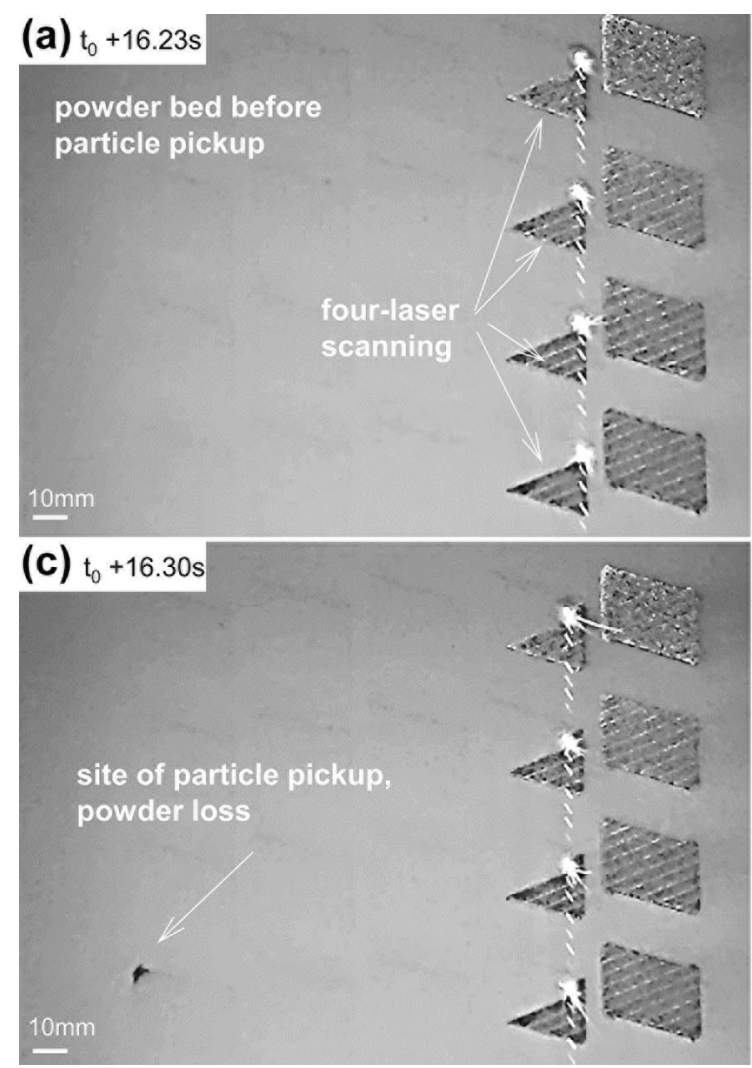
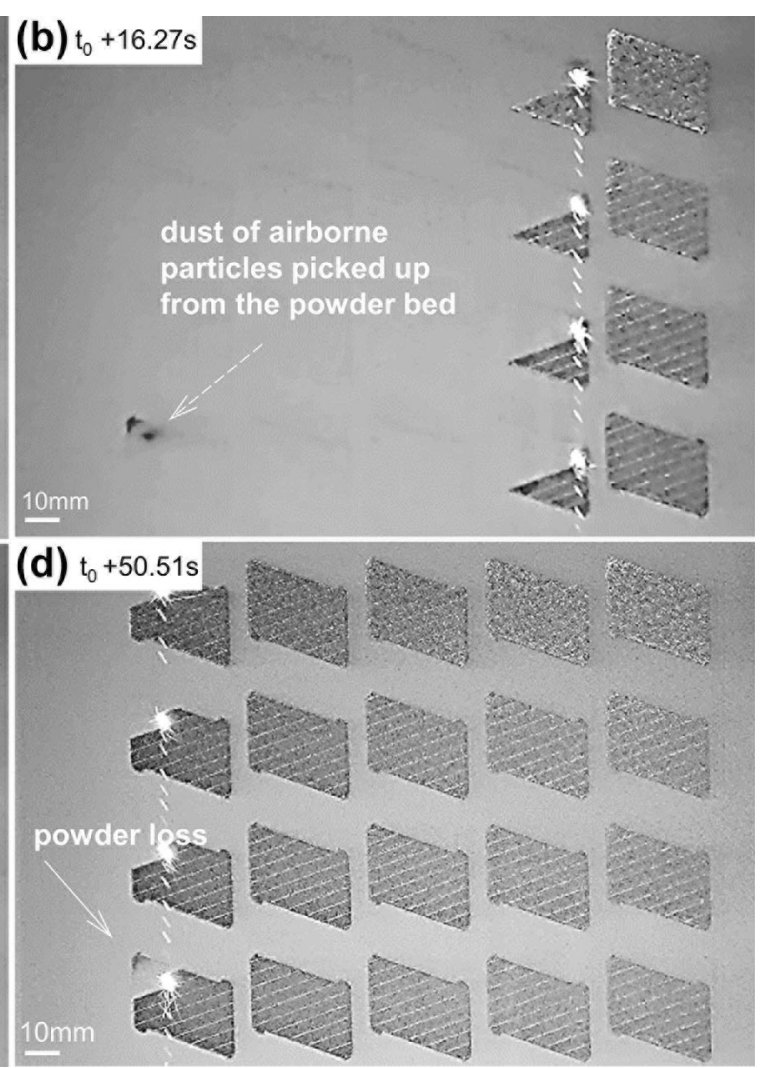

Fig. 9. (a) Particle pickup event captured in a commercial system ("LPBF-X") during laser melting: (a) powder bed before pickup, (b) pickup site and dust forms from particle pickup, (c) powder bed after pickup, (d) pickup site is part of the component and the fluctuation of powder layer thickness can cause solidification defects. Argon flows from left to right side. The pickup site is at the inlet side. $t_{0}$ is the recoating finish time. Pickup happens about $16 \mathrm{~s}$ after recoating.

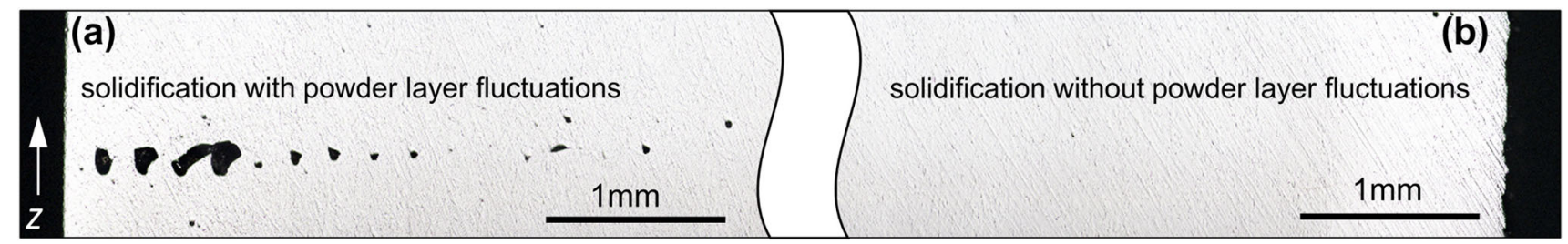

Fig. 10. (a) Defects resulting from fluctuations of powder layer and (b) normal area without fluctuations of the powder layer.

At high gas flow speed, the powder layer thickness fluctuates if particle pickup happens and both lack of fusion and keyhole defects may occur. At the site of powder loss, keyhole defects due to overheating of the melt pool may happen due to successive energy density as there is less material to melt: $E_{\text {effective }}=P /(h v(l-\Delta l))$, where $\Delta l$ is the powder loss due to particle pickup. However, lack of fusion is also possible. The melting may result in less material solidified in the current layer and therefore more powder to be melted in the next layer. The lack of fusion may occur due to increased powder layer thickness (if powder loss does not happen in this layer): $E_{\text {effective }}=P /(h v(l+\Delta l))$, where $\Delta l$ is the increased powder layer thickness due to thinner solidification of less powder in the previous layer. Without knowing the exact fluctuation of powder layer thickness and the threshold of the keyhole generation, it is hard to conclude which kind of defect occurred.

It is worth noting that sometimes defects are regarded as one large cluster of defects if the defects are interconnected or very close to each other. X-ray microtomography is a useful way to reconstruct the $3 \mathrm{D}$ characterization of internal defects, ${ }^{43,44}$ which will be considered in future work. Here, based on the $2 \mathrm{D}$ images, a rule of thumb may be adopted that defects can be clustered and regarded as large defect if the distance to the neighboring defect is smaller than the size of the larger defect. Then, large defect clusters up to hundreds of micrometers can be found in samples with defects formed due to both laser plume attenuation (Fig. 3b) and unstable powder layer (Fig. 10a) at inappropriate gas flow speeds. 
Moreover, these clusters tend to orient perpendicular to the build direction, which implies that they will be more detrimental when applying a load along the build direction. This preferred orientation may also cause anisotropy of mechanical properties.

\section{Gas Flow Speed Range and Flow Field Uniformity}

Regarding the HX powder used in LPBF printing, the lower limit is determined to be $1.5 \mathrm{~m} / \mathrm{s}$. Below $1.5 \mathrm{~m} / \mathrm{s}$, severe plume laser attenuation can result in lack-of-fusion defects. The upper limit is set at $4.8 \mathrm{~m} / \mathrm{s}$, using the lower bound of the $\pm 30 \%$ error band of the predicted $6.8 \mathrm{~m} / \mathrm{s}$ pickup speed.

For lighter alloys with good flowability, the speed range can shrink significantly. For fine Al-alloy and Ti-alloy powder in argon gas, at the transitional point $d_{\mathrm{I}-\mathrm{II}}^{*}$ the powder starts to flow freely but reaches the minimum pickup speed $U_{\text {I-II }}^{*}$ of about $3.5 \mathrm{~m} / \mathrm{s}$ and $4 \mathrm{~m} / \mathrm{s}$, respectively. Applying the lower bound of the $\pm 30 \%$ error band, the upper limits are then set at $2.5 \mathrm{~m} / \mathrm{s}$ and $2.9 \mathrm{~m} / \mathrm{s}$, respectively. If the average speed of $2.87 \mathrm{~m} / \mathrm{s}$ is to be used for AlSi10Mg as proposed by Anwar and Pham, ${ }^{7}$ then the process window does not exist. Processing of light alloy powders can be challenging for LPBF systems. Besides the aforementioned four-beam scanning of free-flowing Ti64 powder in the "LPBF-X" system, processing of Al-alloy is found to be challenging in another commercial system (hereafter called "LPBF-Y"). The AlSi10Mg powder used in the "LPBF-Y" system was sieved with a $100-\mu \mathrm{m}$ mesh and the mean size was about $50 \mu \mathrm{m}$. As shown in supplementary Fig. S-4, both plume particles and powder particles from the feedstock were found on the contaminated laser window, which indicates that both insufficient plume removal and dust of picked up particles from the powder exist during the printing. While this commercial system features dual-laser scanning (1000 W each laser), a large printing area $(800 \mathrm{~mm}$ by $400 \mathrm{~mm})$ and automated powder handling, the production efficiency has to be compromized by reducing the laser power (eventually to about $300 \mathrm{~W}$ ). Therefore, in order to enable high energy inputs (using high power laser or multiple lasers) for high build rates and to enable using free-flowing powder for higher production efficiency, a more uniform gas flow that can effectively remove the plume without picking up particles and forming dust is crucial for industrial productions.

\section{CONCLUSION}

A defect formation mechanism based on effective energy input was proposed to explain the lack-offusion defects resulting from either laser-plume attenuation under low gas flow speeds, or fluctuations of the powder layer thickness under high flow speeds. Secondly, a method based on porosity/defect characterization and particle pickup was proposed to determine the suitable speed range for gas flow in LPBF, including: (1) the lower limit as the threshold below which large lack-of-fusion defects and significant increases of porosity occur in samples built with optimized process parameters; and (2) the upper limit as the particle pickup speed which can be predicted by the Kalman three-zone model.

Measurements of gas flow speeds with an anemometer were used to determine an actual flow speed range suitable for powder-bed-based LPBF processes. Using Ni-alloy Hastelloy X (HX) as an example, a lower limit of $1.5 \mathrm{~m} / \mathrm{s}$ was determined based on porosity results, and an upper limit of $4.8 \mathrm{~m} / \mathrm{s}$ was determined based on particle pickup speed, thereby giving an argon flow speed range of $1.5-4.8 \mathrm{~m} / \mathrm{s}$ for LPBF printing.

To determine the lower limit of flow speed for other powders, future work is required to account for different extents of evaporation of different alloys and different laser energy inputs. For determining the upper limit of flow speed for other powders, the Kalman three-zone model can be used as a useful reference to account for different particle sizes and particle densities. The lower bound of the $\pm 30 \%$ error band is recommended to ensure powder bed stability in LPBF.

\section{ACKNOWLEDGEMENTS}

Haopeng Shen gratefully acknowledges help from Professor Rod Boyer, Dr Paul Wynne, Dr Songmao Chen, Dr Yang Tian, AmPro Innovations, Monash Wind Tunnel and the Laboratory for Simulation and Modelling of Particulate Systems (SIMPAS). Haopeng Shen also acknowledges the use of the facilities at the Monash Centre for Additive Manufacturing (MCAM), the Monash Centre for Electron Microscopy (MCEM) and the Medicines Manufacturing Innovation Centre (MMIC). This research was funded by the Australian Research Council Grant IH130100008 "Industrial Transformation Research Hub for Transforming Australia's Manufacturing Industry through High Value Additive Manufacturing".

\section{ELECTRONIC SUPPLEMENTARY MATERIAL}

The online version of this article (https://doi.org/ 10.1007/s11837-020-04020-y) contains supplementary material, which is available to authorized users.

\section{REFERENCES}

1. K. Kamimuki, T. Inoue, K. Yasuda, M. Muro, T. Nakabayashi, and A. Matsunawa, J. Laser Appl. (2002). https://d oi.org/10.2351/1.1493766. 
2. R. Fabbro, S. Slimani, I. Doudet, F. Coste, and F. Briand, J. Phys. D Appl. Phys. (2006). https://doi.org/10.1088/0022-37 27/39/2/023.

3. J. Greses, P.A. Hilton, C.Y. Barlow, and W.M. Steen, J. Laser Appl. (2004). https://doi.org/10.2351/1.1642636.

4. J. Zou, W. Yang, S. Wu, Y. He, and R. Xiao, J. Laser Appl. (2016). https://doi.org/10.2351/1.4940148.

5. P. Bidare, I. Bitharas, R.M. Ward, M.M. Attallah, and A.J. Moore, Acta Mater. (2018). https://doi.org/10.1016/j.actamat. 2017.09.051.

6. A. Ladewig, G. Schlick, M. Fisser, V. Schulze, and U. Glatzel, Addit. Manuf. (2016). https://doi.org/10.1016/j.addma.2 016.01 .004$.

7. A.B. Anwar and Q.C. Pham, J. Mater. Process. Technol. (2017). https://doi.org/10.1016/j.jmatprotec.2016.10.015.

8. B. Ferrar, L. Mullen, E. Jones, R. Stamp, and C.J. Sutcliffe, J. Mater. Process. Technol. (2012). https://doi.org/10.1016/j. jmatprotec.2011.09.020.

9. P. Wen, Y. Qin, Y. Chen, M. Voshage, L. Jauer, R. Poprawe, and J.H. Schleifenbaum, J. Mater. Sci. Technol. (2019). h ttps://doi.org/10.1016/j.jmst.2018.09.065.

10. M. Schniedenharn, F. Wiedemann, and J.H. Schleifenbaum, Rapid Prototyp. J. (2018). https://doi.org/10.1108/RPJ-07-2 017-0149.

11. E. Rabinovich and H. Kalman, Powder Technol. (2011). h ttps://doi.org/10.1016/j.powtec.2007.07.030.

12. H. Kalman, A. Satran, D. Meir, and E. Rabinovich, Powder Technol. (2005). https://doi.org/10.1016/j.powtec.2005.08.00 9.

13. A. Anantharaman, X. Wu, K. Hadinoto, and J.W. Chew, Chem. Eng. Sci. (2015). https://doi.org/10.1016/j.ces.2015.03. 022 .

14. F.J. Cabrejos and G.E. Klinzing, Powder Technol. (1992). h ttps://doi.org/10.1016/S0032-5910(92)85021-M

15. F.J. Cabrejos and G.E. Klinzing, Powder Technol. (1994). h ttps://doi.org/10.1016/0032-5910(94)02815-X.

16. K.S. Hayden, K. Park, and J.S. Curtis, Powder Technol. (2003). https://doi.org/10.1016/S0032-5910(02)00135-3.

17. A. Ramadan, P. Skalle, and S.T. Johansen, Chem. Eng. Sci. (2003). https://doi.org/10.1016/S0009-2509(03)00061-7.

18. M. Hubert and H. Kalman, Granul. Matter (2004). https://d oi.org/10.1007/s10035-004-0166-x.

19. J. Visser, Powder Technol. (1989). https://doi.org/10.1016/0 032-5910(89)80001-4

20. E. Rabinovich and H. Kalman, Powder Technol. (2008). h ttps://doi.org/10.1016/j.powtec.2007.07.030.

21. Q. Li, V. Rudolph, and W. Peukert, Powder Technol. (2006). https://doi.org/10.1016/j.powtec.2005.10.012

22. G.H. Bagheri, C. Bonadonna, I. Manzella, and P. Vonlanthen, Powder Technol. (2015). https://doi.org/10.1016/j.pow tec.2014.10.015.

23. J.A. Muñiz-Lerma, A. Nommeots-Nomm, K.E. Waters, and M. Brochu, Materials (2018). https://doi.org/10.3390/ma111 22386.

24. R. Baitimerov, P. Lykov, D. Zherebtsov, L. Radionova, A. Shultc, and K.G. Prashanth, Materials (2018). https://doi. org $/ 10.3390 /$ ma11050742.

25. Y. Sun, M. Aindow, and R.J. Hebert, Addit. Manuf. (2018). h ttps://doi.org/10.1016/j.addma.2018.02.011.
26. Z. Liu, C. Huang, C. Gao, R. Liu, J. Chen, and Z. Xiao, J. Min. Metall. Sect. B Metall. (2019). https://doi.org/10.2298/ JMMB181025008L.

27. V. Seyda, D. Herzog, and C. Emmelmann, J. Laser Appl. (2017). https://doi.org/10.2351/1.4983240.

28. L. Markusson, Powder Characterization for Additive Manufacturing Processes (Thesis: Luleå University of Technology, 2017).

29. Q.B. Nguyen, M.L.S. Nai, Z. Zhu, C.N. Sun, J. Wei, and W. Zhou, Engineering (2017). https://doi.org/10.1016/J.ENG.20 17.05.012.

30. J.P. Choi, G.H. Shin, S. Yang, D.Y. Yang, J.S. Lee, M. Brochu, and J.H. Yu, Powder Technol. (2017). https://doi. org/10.1016/j.powtec.2017.01.030.

31. G. Marchese, X. Garmendia Colera, F. Calignano, M. Lorusso, S. Biamino, P. Minetola, and D. Manfredi, Adv. Eng. Mater. (2017). https://doi.org/10.1002/adem.201600635.

32. A. Bauereiß, T. Scharowsky, and C. Körner, J. Mater. Process. Technol. (2014). https://doi.org/10.1016/j.jmatprotec.20 14.05.002.

33. A.M. Beese and B.E. Carroll, JOM (2016). https://doi.org/10. 1007/s11837-015-1759-z.

34. D. Tomus, T. Jarvis, X. Wu, J. Mei, P. Rometsch, E. Herny, J.F. Rideau, and S. Vaillant, Phys. Procedia (2013). https://d oi.org/10.1016/j.phpro.2013.03.154.

35. N.J. Harrison, I. Todd, and K. Mumtaz, Acta Mater. (2015). https://doi.org/10.1016/j.actamat.2015.04.035.

36. M. Hamadou, R. Fabbro, and G. Caillibotte, ICALEO (2004). https://doi.org/10.2351/1.5060385.

37. M. Gao, X. Zeng, and Q. Hu, J. Mater. Process. Technol. (2007). https://doi.org/10.1016/j.jmatprotec.2006.11.019.

38. G. Yablokova, M. Speirs, J. Van Humbeeck, J.P. Kruth, J. Schrooten, R. Cloots, F. Boschini, G. Lumay, and J. Luyten, Powder Technol. (2015). https://doi.org/10.1016/j.powtec.20 15.05.015.

39. C. Pleass and S. Jothi, Addit. Manuf. (2018). https://doi.org/ 10.1016/j.addma.2018.09.023.

40. X.P. Li, K.M. O'donnell, and T.B. Sercombe, Addit. Manuf. (2016). https://doi.org/10.1016/j.addma.2016.01.003.

41. K.V. Yang, P. Rometsch, T. Jarvis, J. Rao, S. Cao, C. Davies, and X. Wu, Mater. Sci. Eng. A (2018). https://doi.org/10.10 16/j.msea.2017.11.078.

42. C. Weingarten, D. Buchbinder, N. Pirch, W. Meiners, K. Wissenbach, and R. Poprawe, J. Mater. Process. Technol. (2015). https://doi.org/10.1016/j.jmatprotec.2015.02.013.

43. R. Cunningham, S.P. Narra, C. Montgomery, J. Beuth, and A.D. Rollett, JOM (2017). https://doi.org/10.1007/s11837-01 6-2234-1.

44. W.E. King, H.D. Barth, V.M. Castillo, G.F. Gallegos, J.W. Gibbs, D.E. Hahn, C. Kamath, and A.M. Rubenchik, J. Mater. Process. Technol. (2014). https://doi.org/10.1016/j.jma tprotec.2014.06.005.

Publisher's Note Springer Nature remains neutral with regard to jurisdictional claims in published maps and institutional affiliations. 